\title{
Application of CFRP with High Hydrogen Gas Barrier Characteristics to Fuel Tanks of Space Transportation System
}

\author{
By Koichi YONEMOTO ${ }^{1)}$, Yuta YAMAMOTO ${ }^{1)}$, Keiichi OKUYAMA ${ }^{2)}$ and Takeo EBINA ${ }^{3)}$ \\ ${ }^{1)}$ Department of Mechanical and Control Engineering, Kyushu Institute of Technology, Kitakyushu, Japan \\ ${ }^{2)}$ Department of Electronics and Control Engineering, Tsuyama National College of Technology, Tsuyama, Japan \\ ${ }^{3)}$ Research Center for Compact Chemical Process, National Institute of Advanced Industrial Science and Technology, Sendai, Japan
}

(Received April 30th, 2008)

In the future, carbon fiber reinforced plastics (CFRPs) with high hydrogen gas barrier performance will find wide applications in all industrial hydrogen tanks that aim at weight reduction; the use of such materials will be preferred to the use of conventional metallic materials such as stainless steel or aluminum. The hydrogen gas barrier performance of CFRP will become an important issue with the introduction of hydrogen-fuel aircraft. It will also play an important role in realizing fully reusable space transportation system that will have high specific tensile CFRP structures. Such materials are also required for the manufacture of high-pressure hydrogen gas vessels for use in the fuel cell systems of automobiles. This paper introduces a new composite concept that can be used to realize CFRPs with high hydrogen gas barrier performance for applications in the cryogenic tanks of fully reusable space transportation system by the incorporation of a nonmetallic crystal layer, which is actually a dense and highly oriented clay crystal laminate. The preliminary test results show that the hydrogen gas barrier characteristics of this material after cryogenic heat shocks and cyclic loads are still better than those of other polymer materials by approximately two orders of magnitude.

Key Words: Carbon Fiber Composites, Materials-Clay, Hydrogen Gas Barrier

\section{Introduction}

In order to enable further and rapid developments in space travel, it is essential to reduce the cost of entering space to one-tenth, or ideally one-hundredth, of that incurred in the use of conventional expendable rockets or American Space Shuttles; this can be realized by using fully reusable logistics and human transportation systems. One of the key technologies that can enable cost reductions is the reduction in the critical weight that can be realized by employing carbon fiber reinforced plastics (CFRPs) in the fabrication of the structures of space transportation system; these materials have specific strengths that are superior to those of the aluminum materials that are currently widely used in the manufacture of aircraft. Since fuel accounts for $90 \%$ of the initial launch mass of a space transportation system, most of the volume of the vehicle's structure is occupied by fuel tanks used for storing fuels such as liquid hydrogen and liquid oxygen. Thus, the realization of fuel tanks manufactured from CFRPs is expected to be a breakthrough that will result in a weight reduction; this in turn will lead to a cost reduction.

However, the experience gained from the failure of the X-33 project - a test vehicle of the fully reusable space transportation system planned to be the successor of the partial reusable Space Shuttle-has clarified the difficulties that would be involved in realizing a cryogenic composite tank for the storage of liquid hydrogen fuel ${ }^{1)}$. The cryogenic composite tank lobes were sandwich constructions comprising honeycomb cores bonded by inner and outer face sheets. During the proof test, one of the inner face sheets separated from the sandwich honeycomb cores due to the extensive microcracking that was induced by a combination of thermal and mechanical loads. The hydrogen apparently permeated into the honeycomb cores, resulting in the cryopumping of the air within, in turn leading to delamination at the interface of the face sheets ${ }^{2)}$.

Japan Aerospace Exploration Agency (JAXA) started the development of cryogenic hydrogen composite tank since late in the 1990s. One of the major results is the pressurization test of fully composite model tank in cryogenic temperature to demonstrate its feasibility for the future reusable space transportation system ${ }^{3)}$. Another interesting development is metal-lined composite cryogenic tank, the technology of which has been proven by repeated flights of a vertical takeoff and landing experimental reusable rocket ${ }^{4}$.

Since the hydrogen gas permeability of composite materials remains one of the major concerns in the design of hydrogen tanks, various structural concepts involving the use of materials such as thin aluminum sheets or polymer compounds as the hydrogen gas barrier liners have been proposed thus far. The former concept has been successfully employed for realizing super-high-pressure hydrogen tanks - capable of withstanding pressures up to 700bars - for automobiles in combination with a filament winding composite technique in order to withstand high hoop stress. However, this concept cannot be directly applied to the manufacture of cryogenic composite tanks for aircraft or space transportation system due to the large difference in the thermal expansion ratios of the composite material and metal. The latter concept using liquid polymer crystal polymers is currently being researched from the viewpoint of application as a bonding 
interface between the composite lobe and the polymer liner.

This paper introduces a new composite material-a highly oriented clay crystal laminate - that can enable a CFRP to possess a high hydrogen gas barrier performance ${ }^{5)}$, and discusses on the recent results of preliminary hydrogen gas permeability tests after cryogenic heat shocks and cyclic loads.

\section{Highly Oriented Clay Crystal Laminate “CLAIST"}

The Research Center for Compact Chemical Processes at the National Institute of Advanced Industrial Science and Technology (AIST) has invented a unique flexible film called "Claist" (Clay + AIST) that mainly comprises clay with a small amount of an organic binder ${ }^{6-9)}$. Claist is a new type of film material that is currently being developed by AIST for applications as a gas barrier in high-temperature regions where other conventional materials cannot be used. Claist is manufactured by densely laminating platelet-shaped clay crystals of $1 \mathrm{~nm}$ thickness with a highly oriented structure, as shown in Fig. 1.

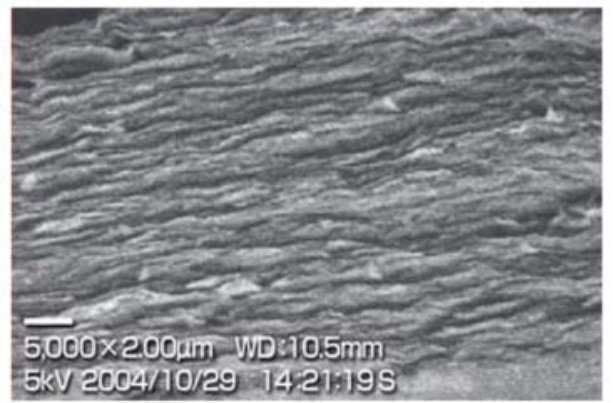

Fig. 1. Densely laminated platelet-shaped clay crystals called Claist

Since only a small amount of organic binder is used, Claist has a very high performance, especially in terms of the hydrogen gas characteristics, that are distinctly superior to those of conventional nanocomposite materials, which mainly comprise organic materials. The film thickness can be controlled in the range from 10 to $100 \mu \mathrm{m}$, and the film has a high gas barrier property against inorganic gases such as hydrogen as well as oxygen under high-temperature conditions. In fact, the developed film maintains extremely high barrier characteristics against all inorganic gases over a wide range of temperatures up to 600degrees.

The permeability of dry Claist to other inorganic gases such as helium, oxygen, or nitrogen was under the detection limits at room temperature. The permeability is extremely low as compared to that of conventional engineering plastics (e.g. Nylon-6 with an oxygen permeability of $\left.18 \mathrm{cc} / \mathrm{m}^{2} \times 24 \mathrm{~h} \times \mathrm{atm}\right)$, and comparable to that of aluminum foil (oxygen permeability $=0$ ).

The mechanism used to achieve such high gas barrier characteristics is shown in Fig. 2. For example, hydrogen gas cannot permeate through the clay crystals, but can permeate through the organic binders. Since Claist mainly comprises highly oriented clay crystals, the gas barrier characteristics become more effective than those of other organic materials.

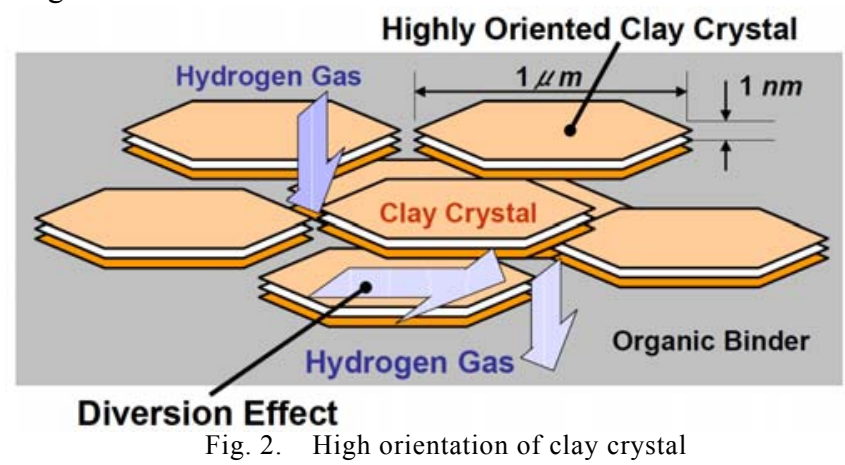

Claist can be used as a self-standing film. Its flexibility is similar to that of ordinary copying paper, and it can be cut, folded, and bent as desired (Fig. 3).

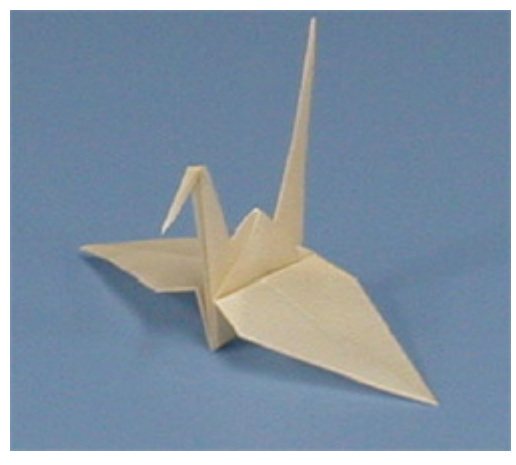

Fig. 3. Origami crane made from Claist

It is also noncombustible and has an oxygen index (OI) exceeding $94 \%$. Due to these unique properties, Claist is expected to find a wide range of applications. For example, it can be used as wrapping film under high-temperature conditions, and it can be effectively applied for leak prevention in production line piping connections in a wide range of fields in the chemical industry. In addition, it may potentially find applications in gas barrier layers, substrate films, and membranes for solar cells and fuel cells.

Claist is expected to find applications in high barrier films that do not include aluminum foil, and it is a promising candidate as a replacement for asbestos, the use of which has recently raised health concerns. Moreover, the successful development of transparent Claist made from high-transparency synthetic clay has led to an increased potential for applications to flexible display materials, packaging materials, and similar products that require transparency, as shown in Fig. 4.

Claist is a remarkable material in that it is eco-friendly; no waste is produced as a byproduct in the manufacturing process and the main component of the gas barrier film is clay crystals. When natural clay is used as the raw material, the production cost is comparable to that of general engineering plastics. At present, a mass production technique is being developed, and applied researches on individual applications are in progress. 


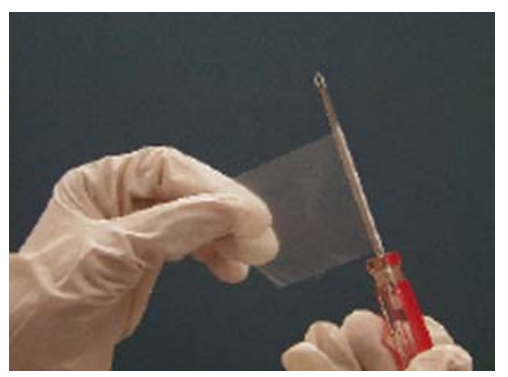

Fig. 4. Example of transparent-type Claist

\section{Claist Compound Carbon Fiber Reinforced Plastics}

Thus far, two types of compound processes for the use of Claist with CFRP have been studied, as shown in Fig. 5. In the first process, a Claist film is simply sandwiched between CFRP prepregs. The sandwich is then placed in an autoclave for curing at a specified high temperature. In the second process, a Claist layer is first fabricated in the lamination layer of a CFRP prepreg, as shown in the figure. Then, the Claist compound CFRP prepreg is placed in an autoclave for curing.

Test coupons have been manufactured by the first compound process, involving simple sandwich forming. The prepregs employed for sandwich forming were PYLOFIL\#380, supplied by Mitsubishi Rayon Co., Ltd., comprising cloth carbon fibers. A thin Claist film having a thickness of approximately $70-90 \mu \mathrm{m}$ was first placed over the three prepreg sheets. Another set of three prepreg sheets was then placed on the Claist film, as shown in Fig. 6. Next, a hot press was used for curing. The setup of the hot press is shown in Fig. 7. The pressure level was set to approximately $0.6 \mathrm{MPa}$. The temperature is first controlled so that it has a gradient of 3 degrees / min. The temperature was maintained at 130 degrees for $90 \mathrm{~min}$. Then, the test coupon was cooled down to room temperature in the atmosphere. The test coupon had a length, width, and thickness of $150 \mathrm{~mm}, 100 \mathrm{~mm}$, and approximately $1 \mathrm{~mm}$, respectively. A cut-off part of the test coupon is shown in Fig. 8.

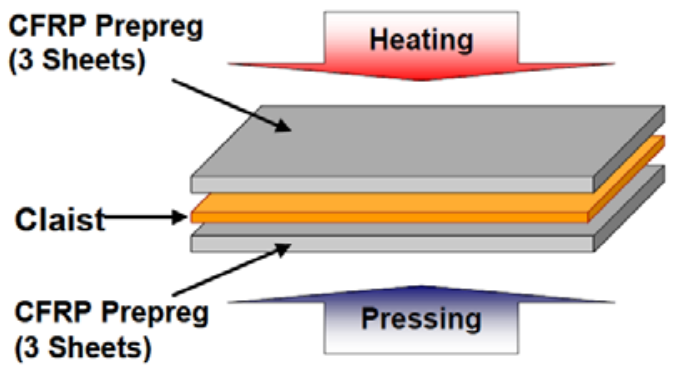

Fig. 6. Test coupon of Claist compound CFRP

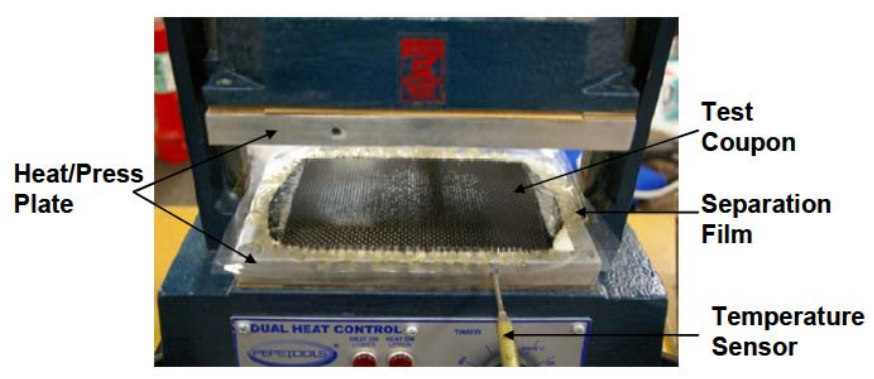

Fig. 7. Hot press setup

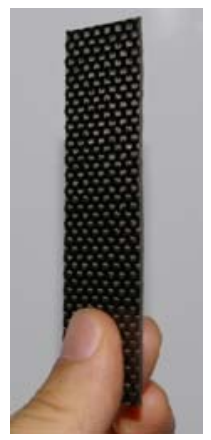

Fig. 8. Cut-off part of test coupon

The optical and electron micrographs of Claist compound CFRP are shown in Fig. 9. In the left-hand side of the figure, Claist is seen as a dense and dark layer between the upper and lower CFRP layers, where the cross sections of the carbon fibers appear as a scattering

Compound Process 1.

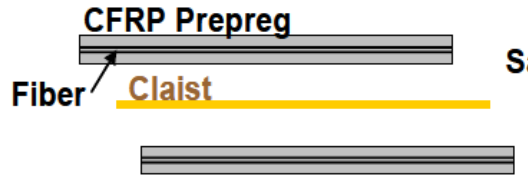

Sandwich

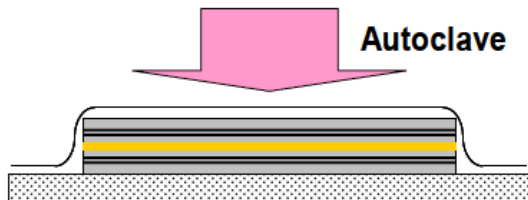

Compound Process 2.
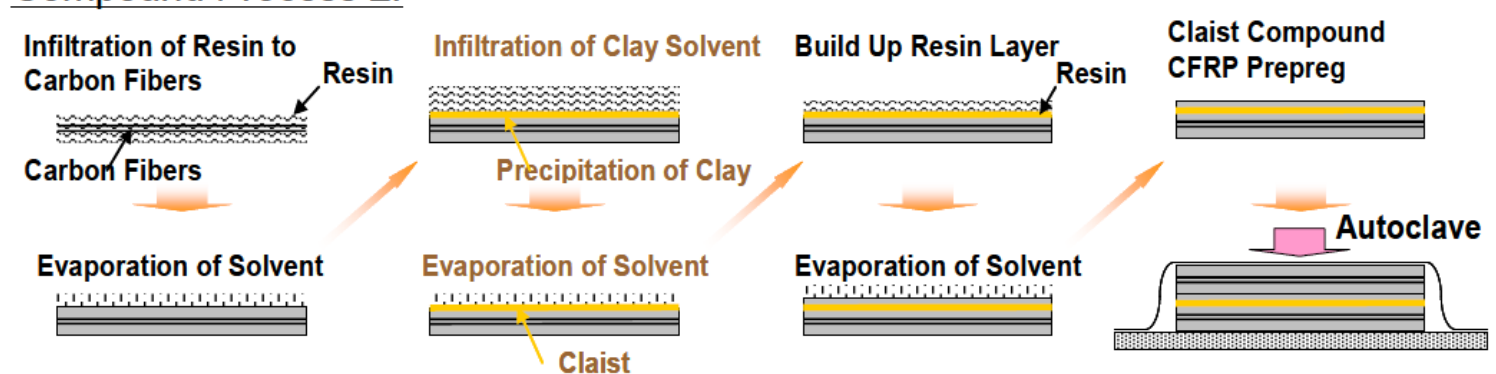

Fig. 5. Claist compound process 
of round and bright particles. The interface between Claist and CFRP can be observed in the electron micrograph shown in the right-hand side of the figure. The dense and highly oriented crystals are indistinguishable even in the electron micrograph. However, the organic binder fills in the roughness of CFRP interface to create a tight mechanical bond by the anchor effect.

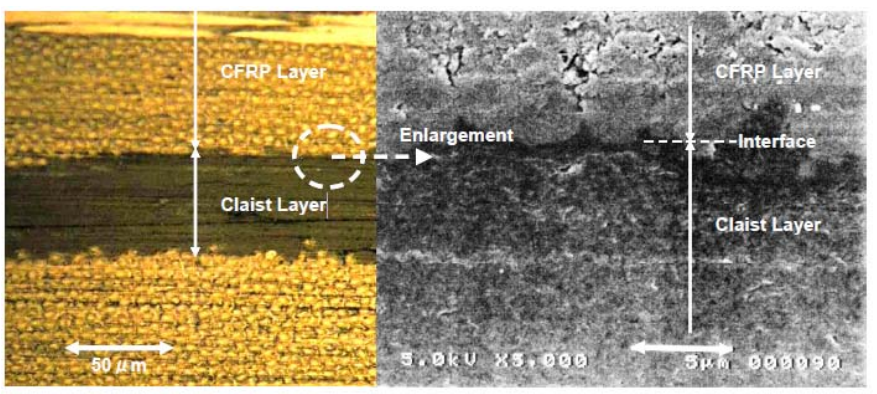

(a) Optical micrograph

(b) Electron micrograph

Fig. 9. Micrographs of Claist compound CFRP

\section{Hydrogen Gas Permeability Test}

\subsection{Test coupons}

The hydrogen gas barrier characteristics of CFRP can be deteriorated due to the growth of micro cracks caused by various kinds of damage. One of the damages is cryogenic thermal shock at fueling of liquid hydrogen, and the other one is static or dynamic loads applied during flight.

In order to investigate the effect of cryogenic thermal shocks and applied loads on the hydrogen gas barrier characteristics, two kinds of test coupon were provided for the permeability tests. A series of test coupon were damaged by cyclic cryogenic thermal shocks using liquid nitrogen. Another series of test coupon were damaged by cyclic loads applied by fatigue test facility. The summary of the test coupons are shown in Table 1.

\begin{tabular}{llc}
\multicolumn{2}{c}{ Table 1. } & Hydrogen permeability test coupons \\
\hline \hline \multirow{2}{*}{ No Damage } & CFRP only & No. of Cycles \\
\cline { 2 - 3 } & Claist compound CFRP & - \\
\hline $\begin{array}{l}\text { Cryogenic } \\
\text { Shocks }\end{array}$ & Liquid Nitrogen & 100 \\
\hline \multirow{2}{*}{ Tensile Loads } & $\begin{array}{l}5,000 \mu \mathrm{Strain} \\
(327.5 \mathrm{MPa})\end{array}$ & 1000 \\
\cline { 2 - 3 } & $\begin{array}{l}7,000 \mu \mathrm{Strain} \\
(458.8 \mathrm{MPa})\end{array}$ & 1000 \\
\hline \hline
\end{tabular}

The plane form of test coupon used for cyclic cryogenic thermal shocks is shown in Fig. 10. The thickness is about $1 \mathrm{~mm}$. The liquid nitrogen, the boiling temperature of which is -196 degrees of Celsius, was employed to cause the cyclic cryogenic thermal shock. The test coupon was dropped in a vessel filled with liquid nitrogen, and then pulled out from the vessel to recover the room temperature. This procedure was repeated up to an aiming cycles by an automatic actuator system as shown in Fig. 11.

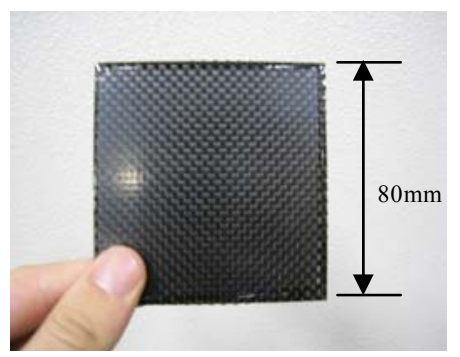

Fig. 10. Test coupon for cryogenic thermal shocks

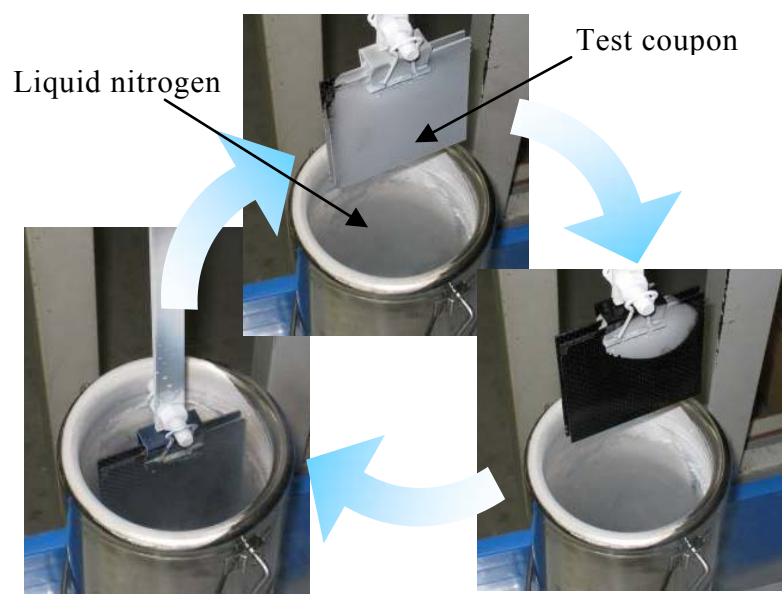

Fig. 11. Cyclic cryogenic thermal shock procedure

The plane form of test coupon used for cyclic loads is shown in Fig. 12. The thickness is also about $1 \mathrm{~mm}$. The cyclic loads to certain strain levels ware applied using a fatigue test facility as shown in Fig. 13. The stress ratio was 0.1 , and the load frequency was $2 \mathrm{~Hz}$. The Young's modulus of the test coupons was first measured, and found 65.5GPa as shown in Fig. 14.

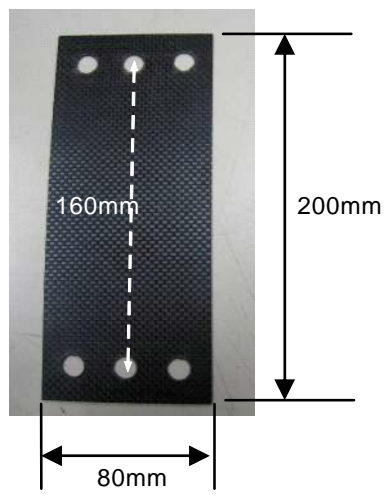

Fig. 12. Test coupon for cyclic loads
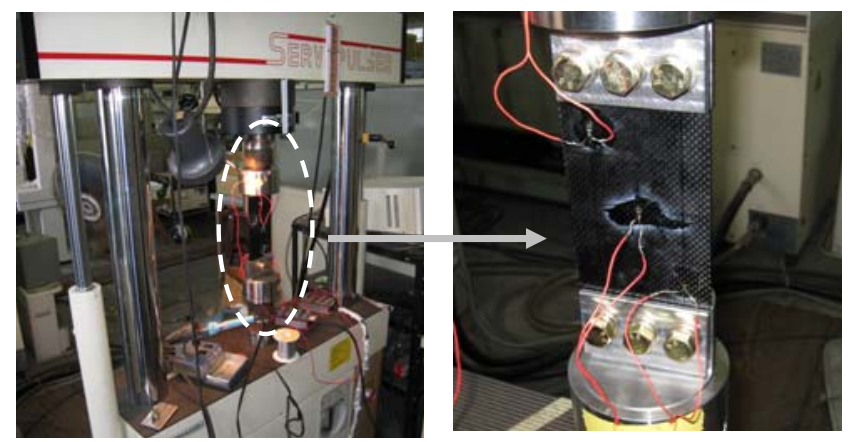

Fig. 13. Fatigue test facility 


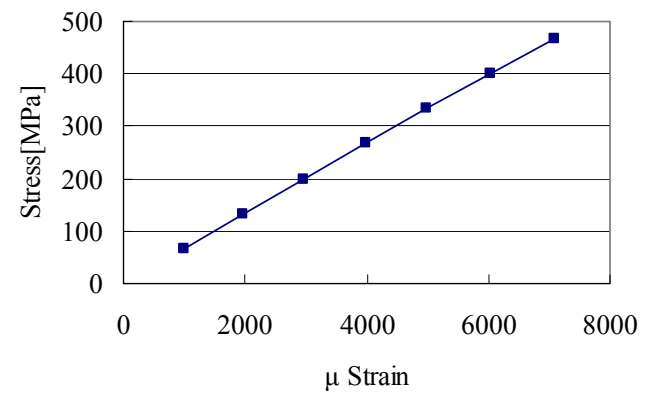

Fig. 14. Stress-strain curve of test coupon

\subsection{Test facility}

Hydrogen gas permeability tests of Claist compound CFRP were conducted using a gas chromatography method, as shown in Fig. 15. Hydrogen gas is introduced to the pressure side of the permeability test coupon with a maximum pressure level of $700 \mathrm{kPa}$, while a vacuum is maintained on the other side. The hydrogen gas permeating through the test coupon is measured by chromatography.

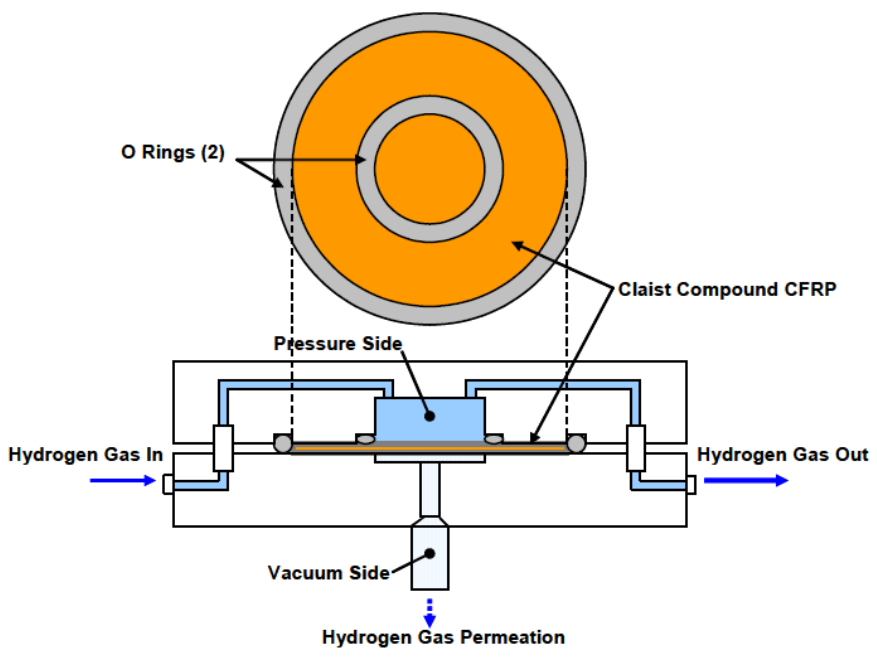

Fig. 15. Hydrogen gas permeability test

The plane form of the test coupon is shown in Fig. 16. The permeation analysis system is GTR-10XASS made by GTR Tech Corporation; the system is shown in Fig. 17.

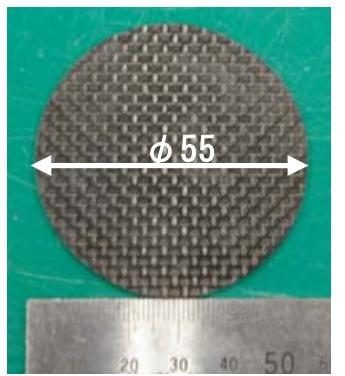

Fig. 16. Plane form of permeability test coupon

The test time was determined for the gas chromatography to obtain sufficient volume of hydrogen permeation gas above the detection limit of with accuracy. If the permeability is very low, the test time becomes significant long. In order to reduce the test time, the hydrogen gas was pressurized up to the maximum limit. The test time, which is a preset parameter determined by trial and error for the first time, has been taken as long as possible to satisfy the detection condition.

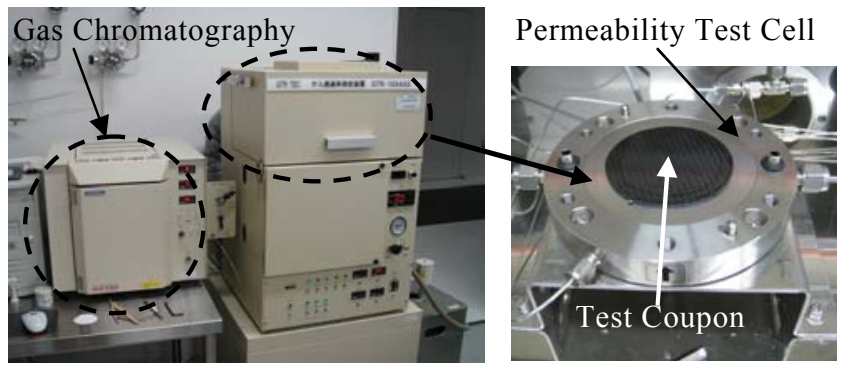

Fig. 17. Permeation analysis system

\subsection{Test results}

The hydrogen gas permeability test results of the Claist compound CFRP are summarized in Table 2. The gas permeability is defined by the amount of permeation volume per unit area, time, pressure, and reciprocal of thickness. The hydrogen gas permeability data are compared with that of CFRP alone and the coupons which received several damages as well. In addition to these gas barrier characteristics, the permeability data of the hydrogen fuel hose invented by Tokai Rubber Industries, Ltd. ${ }^{10)}$, liquid crystal polyesters resin for high-pressure hydrogen reservation tank invented by Toray Industries, Inc. ${ }^{11)}$, virgin IM7/977-2/AF-191 ${ }^{12)}$, EVAL resin ${ }^{13)}$ are also shown for comparison.

The CFRP made of PYLOFIL\#380 without the Claist compound has hydrogen gas permeability similar to that of virgin IM7/977-2/AF-191. The hydrogen gas permeability of Claist compound CFRP is two or three orders of magnitude lower than that of CFRP alone and the liquid crystal polyesters, one order or two orders than that of EVAL. It is also remarkable that very high gas barrier characteristics are maintained for the coupons damaged by cryogenic thermal shocks and cyclic loads except those of 1000 cycles of cryogenic thermal shock.

The six specimens out of eight that made of Claist compound CFRP after cyclic loading exhibit lower hydrogen gas permeability than those without damage. But the other two specimens after the cyclic loading show higher hydrogen gas permeability. The hydrogen gas barrier characteristics of Claist compound CFRP is superior to the other polymers, and it took so many measurement hours to detect such a small quantity of permeation gas. Since the permeability tests were conducted in the critical level near the detection limit of chromatography, the measured data even under same damage condition may vary within the limits of measurement error. Therefore it can not be concluded now that the Claist compound CFRP after cyclic loading has lower hydrogen gas permeability than that without loading. 
Table 2. Test results

\begin{tabular}{|c|c|c|c|c|c|c|}
\hline & Test Conditions & & $\begin{array}{c}\text { Thickness } \\
{[\mathrm{mm}]}\end{array}$ & $\begin{array}{c}\text { Pressure } \\
{[\mathrm{kPa}]} \\
\end{array}$ & $\begin{array}{c}\text { Test Time } \\
{[\mathrm{min}]} \\
\end{array}$ & $\begin{array}{l}\text { Hydrogen Gas Permeability } \\
{\left[\times 10^{-16} \mathrm{~mol} \cdot \mathrm{m} /\left(\mathrm{m}^{2} \cdot \mathrm{s} \cdot \mathrm{Pa}\right)\right]}\end{array}$ \\
\hline \multirow{3}{*}{$\begin{array}{l}\text { No } \\
\text { Damage }\end{array}$} & CFRP without Claist & - & 1.061 & 709.3 & - & 0.529 \\
\hline & \multirow{2}{*}{ CFRP with Claist } & \multirow{2}{*}{-} & 1.130 & 709.3 & 3600 & 0.000488 \\
\hline & & & 1.155 & 709.3 & 3600 & 0.001077 \\
\hline \multirow{4}{*}{$\begin{array}{l}\text { Cryogenic } \\
\text { Thermal } \\
\text { Shocks }\end{array}$} & Liquid Nitrogen & \multirow{2}{*}{100 Cycles } & 1.171 & 709.3 & 960 & 0.000575 \\
\hline & Temperature & & 1.157 & 709.3 & 1440 & 0.000106 \\
\hline & Liquid Nitrogen & \multirow{2}{*}{1000 Cycles } & 1.203 & 405.3 & 60 & 27.823 \\
\hline & Temperature & & 1.185 & 405.3 & 60 & 11.060 \\
\hline \multirow{8}{*}{$\begin{array}{l}\text { Tensile } \\
\text { Load }\end{array}$} & \multirow{4}{*}{$5000 \mu$-Strain } & \multirow{2}{*}{1000 Cycles } & 1.166 & 709.3 & 2160 & 0.002844 \\
\hline & & & 1.178 & 709.3 & 2880 & 0.000055 \\
\hline & & 10000 & 1.161 & 709.3 & 2880 & 0.000106 \\
\hline & & Cycles & 1.150 & 709.3 & 2880 & 0.000098 \\
\hline & \multirow{4}{*}{$7000 \mu$-Strain } & \multirow{2}{*}{1000 Cycles } & 1.153 & 709.3 & 2880 & 0.000036 \\
\hline & & & 1.149 & 709.3 & 2880 & 0.000061 \\
\hline & & 10000 & 1.161 & 709.3 & 1440 & 0.025100 \\
\hline & & Cycles & 1.162 & 709.3 & 1440 & 0.000289 \\
\hline \multicolumn{3}{|c|}{ Hydrogen Fuel Hose ${ }^{10)}$} & - & - & - & 33.49 \\
\hline \multicolumn{3}{|c|}{ Liquid Crystal Polyesters Resin ${ }^{11)}$} & - & - & - & 0.625 \\
\hline \multicolumn{3}{|c|}{ Virgin IM7/977-2/AF-191 ${ }^{12)}$} & - & - & - & 0.4 \\
\hline \multicolumn{3}{|c|}{ EVAL Resin ${ }^{13)}$} & - & - & - & 0.031 \\
\hline
\end{tabular}

\section{Conclusions}

The superior hydrogen gas barrier characteristics of Claist compound CFRP are confirmed by conducting permeability tests. Its performance is better than that of any previously reported polymer material by approximately two or three orders of magnitude. The cyclic loads did not make any influence on the hydrogen gas barrier characteristics. However, the hydrogen gas permeability increased drastically for the test coupons damaged by 1000 cyclic thermal shocks. The deterioration mechanism of the hydrogen gas barrier performance is now under research. The simple concept of incorporating a highly oriented clay crystal layer in CFRP may lead to the realization of a new type of hydrogen composite tank that has higher hydrogen gas barrier performance.

\section{Acknowledgments}

A part of the tests was conducted under the contract with JAXA (Japan Aerospace Exploration Agency). The authors would like to express their gratitude to Dr. Toshio Ogasawara of the Advanced Composite Technology Center and Mr. Ryoma Yamashiro of the Space Transportation System Research and Development Center, for their kind supports with regard to the tests.

\section{References}

1) Rayu, I. S.: NASA Langley Damage Tolerance Experiences, FAA Symposium on Composite Damage Tolerance and Maintenance, July 2006.

2) Rivers, H. K. and Sikora, J.G.: Detection of Hydrogen Leakage in a Composite Sandwich Structure at Cryogenic
Temperature, Journal of Space and Rockets, 39, (2002), pp.452-459.

3) Morimoto, T., Shimoda, T., Morino, Y., Hayashi, Y., Yokozeki, T. and Ishikawa, T.: Pressurizing Test of CFRP Model Tank in Cryogenic Temperature, AIAA/NAL-NASDA-ISAS $10^{\text {th }}$ International Space Planes and Hypersonic Systems and Technologies Conference, AIAA 2001-1882, April 24-27, 2001

4) Higuchi, K., Takeuchi, S., Sato, E., Naruo, Y., Inatani, Y., Namiki, F., Tanaka, K. and Watabe, Y.: Development and Flight Test of Metal-lined CFRP Cryogenic Tank for Reusable Rocket, Acta Astronautica, 57 (2005), pp.432-437.

5) Yonemoto, K., Yamamoto, Y., Ebina, T. and Okuyama, K.: High Hydrogen Gas Barrier Performance of Carbon Fiber Reinforced Plastic with Non-metallic Crystal Layer, SAMPE'08, May 18-22, 2008.

6) Ebina, T.: Clay-based Gas Barrier Film 'Claist' Development of Next-Generation High-Performance Heat-Resistant Film, National Institute of Advanced Industrial Science and Technology, Annual Report 2004-2005, 2005.

7) Ebina, T.: Development of 'Claist' - a Flexible Heat-Resistant Inorganic Film, National Institute of Advanced Industrial Science and Technology, AIST Today, No.18, 2005.

8) Ebina, T. and Mizukami, F.: Flexible Transparent Clay film with Heat Resistant and High Gas Barrier Properties, Advanced Materials, 19 (2007), pp. 2450-2453.

9) Tetsuka, H., Ebina, T., Nanjo, H. and Mizukami, F.: Highly Transparent Flexible Clay Films Modified with Organic Polymer: Structural Characterization and Intercalation Properties, Journal of Material Chemistry, 17 (2007), pp. 3545-3550.

10) Japan Patent Office, Publication of Patent Applications: JP 2002-168377 2004.6.14

11) Japan Patent Office, Publication of Patent Applications: JP 2005-126651 2005.5.19.

12) Stokes, E.H.: Hydrogen Permeability of Polymer Based Composite Tank Material Under Tetra-Axial Strain, $5^{\text {th }}$ Conference on Aerospace Materials, Processes, and Environmental Technology (AMPET), Sept. 16-18, 2002.

13) EVAL by Kuraray Co. Ltd., Technical Document No. A-1006. 